\title{
A travel plan as a tool for modifying university staff and students' travel behaviour towards sustainable practices
}

\author{
A. Khan, M. Mohammadzadeh \& A. Syam \\ School of Architecture and Planning, University of Auckland, \\ New Zealand
}

\begin{abstract}
Travel Demand Management (TDM) techniques mainly focus on reducing the number of single occupant car trips and encourage people to use more efficient and sustainable modes such as buses, cycles, and walking. Travel plan is being used as a Travel Demand Management tool around the world in recent times. Medium to large organisations have started to develop travel plans for their employees with a view to modifying their travel behaviour. If the commuting behaviour of a large number of employees could be changed through travel plans it could have a huge impact on reducing congestion and road transport related pollution.

Universities can attract a large number of trips from the students and staff. On many issues universities act as a role model. If the universities can modify the travel habits of students and staff through travel plans, they can not only have positive effects on the city road network and environment but also encourage other organisations to follow suit. This study critically reviews the travel plans of a few universities around the world from sustainability perspectives. It critiques the basis of adopting policies and attempts to find the common as well as unique features of the measures with a view to identifying the best practices. Travel plans are still a new concept and there are hardly any guidelines on preparing them. This research would help universities to modify or develop effective travel plans and lead others to adopt sustainable practices.
\end{abstract}

Keywords: travel plan, TDM, university. 


\section{Introduction}

Conventional transportation planning had focused on increasing the supply of transportation facilities to match the ever-rising demand [1]. The transport planners have started to realise the shortcomings of this approach in recent times [2]. This approach has given preference to cars over other modes and has led to congestion, environmental pollution, depletion of fuel reserve, and large amount of land use being dedicated to car-related infrastructure such as highways and parking lots [2-4]. These are all unsustainable outcomes of the traditional planning approach. Sustainable transportation planning initiatives attempt to revert this trend [3]. Travel Demand Management (TDM) techniques are being increasingly applied all over the world by the transport planners as the provision for transport infrastructure and services can hardly keep pace with the everincreasing travel demand [1]. TDM techniques aim at taking sustainable approaches in managing travel demand. They mainly focus on replacing the cartrips by efficient modes and if possible eliminate the need to travel.

Medium to large organisations are preparing and implementing travel plans with a view to modifying the commuting habits of their staff towards sustainable practices [5]. They are adopting travel plans both voluntarily and under compulsion. These travel plans tend to apply a combination of different TDM techniques to serve their purposes. Universities are generators of a huge of amount traffic $[6,7]$. There has been a significant increase in the number of students and staff in the universities over the last 50 years [8]. Moreover, in line with the trend for overall population, car ownership rate and use have risen for students and staff in this period. Daily commute to the universities by the large number of students and staff can create a lot of impacts on the road network, environment and surrounding communities, and huge demand for parking spaces if they resort to unsustainable practices. The scale of the impacts can be more felt if the university is located in or near the Central Business District (CBD) of a major city.

Travel plans are still a novel idea. Universities are often places for trying out new ideas. On many occasions universities take a leading role in changing the rest of the society $[7,8]$. By adopting travel plans universities can benefit itself, its staff, students and the community. They have the potential to have long term impacts as students are likely to carry forward the travel habits into the next phase of their life when they start working [7]. They can encourage other organisations to prepare and implement travel plans and show them the ways of doing them. This paper reviews the travel plans of five universities from sustainability perspectives. These universities are the University of Auckland (UoA), Auckland University of Technology (AUT) and Victoria University of Wellington (VUW) in New Zealand, RMIT University (RMIT) in Australia and University of Leeds (UL) in the UK. The context, aims and key TDM measures of these travel plans are identified and discussed. The lessons learnt from these travel plans could be useful for other universities considering preparing or updating their travel plans. 


\section{TDM measures and travel plans}

TDM measures can be of two broad types. The ones which encourage people to switch to sustainable travel modes are known as pull measures and ones which force people not to use unsustainable travel modes are known as push measures. The common measures under these two categories are briefly discussed below.

One of the major ways to entice car drivers to leave their cars and opt for buses, trains, and ferries is to make public transport attractive [4]. Of these public transport modes, buses are flexible in terms of routes and feature commonly in the travel plans of universities. Commuters can be encouraged to use buses by increasing its network coverage and frequency of service, reducing journey time and making fare attractive. Additional features like quick boarding through smart cards, modal and service integration, sheltered bus stops and real time information add to its attractiveness. Buses not only use road space efficiently, they produce less pollution compared to cars and force people to undertake some physical activities by involving walking at either end of the trips [9].

Active modes such as cycling and walking do not have any negative environmental impacts [10]. They produce a lot of health benefits by involving some physical activities [9]. Cycles are efficient as they use minimum space on roads and for parking [8]. The common features warranted by the cyclists and pedestrians are safe and convenient routes [4]. Cyclists, in addition, desire safe parking facilities and showers. Dedicated cycle lanes on roads are ways to provide safe and convenient routes. Well-lit and direct pedestrian routes with well-maintained footpaths encourage people to walk during day and night. Both pedestrians and cyclists can be given preference at intersections.

The impacts of car travel can be somewhat reduced by having more than one person in the car during commuting [2]. Car-pooling can be arranged among people who live close to one another and commute to the same place. The arrangement can be made informally by people known to each other or initiated by the employer or the council through ride-matching database [1].

Transport-related discussion is never complete without a mention of land uses. Mixed land uses reduce the need to travel by car and enable people to find most of their essential facilities within their walking distance [4]. Compact development usually results in more people living near public transport nodes and contributes to its patronage [1].

Push measures need to be applied side by side of pull measures to ensure change in travel behaviour. Solo car driving can be made less attractive through parking measures [4]. These measures mainly involve two types of actions. The first one is to increase the parking fee and the second one by reducing the number of parking spaces or not increasing the supply of parking with the ever-increasing demand [2]. The success of parking measures depends on whether suitable parking facilities are available within the walking distance of the site. Parking measures can give preferential treatment to car-poolers by offering lower parking fee and/or reserved parking spaces. 
Compared to switching modes, the measures that are more effective are the ones that eliminate the need to travel. For example, telecommuting allows people to work from home [1]. Along with push and pull measures, TDM measures are more effective when they are supported by well-planned campaigns [7]. Commuters need to be motivated to change their travel behaviour. They need to be educated about the adverse impacts of commuting by cars and benefits of sustainable travel. They need to be provided with information about alternative modes so that they find it easy to shift from one mode to the other. The information can be provided in many ways including pamphlets and Internet and in many formats such as walking maps and bus timetables.

Travel plans are documents adopted by medium to large organisations, which describe the approaches for the employees to commute to the office in a sustainable way [5]. They have been started to be applied in recent years. The approaches in travel plans are mainly based on the TDM measures. These measures are given priority and applied in different ways by the organisations, according to their context and needs. As the tool is still new, it will be worthwhile to look at the travel plans of a few universities to identify common and unique features which can act as lessons for making and updating travel plans by the universities.

\section{Transportation issues at the universities}

A number of studies have been conducted in universities around the world with some focusing on transportation issues. For the last few years universities have been taking initiatives to reduce the modal share of cars in favour of other modes for commuting to the campuses [10]. These initiatives have been taken to serve variety of purposes and they have the potential to benefit not only the universities but also its staff and students, and community at large. A high proportion of these initiatives has taken the form of travel plans.

One of the main reasons for the universities to consider strategies for curbing car use is because universities face problems in providing parking lots due to shortage of space and high cost of constructing multilevel parking facilities [8]. Cost of parking structures could be in the order of US $\$ 15,000$ to $\$ 30,000$ for each car and it can result in huge capital expenditure for the universities. For example, the University of Arizona had to spend $\$ 17$ million on a recent parking structure. Providing subsidised free public transport is often a more costeffective option. There is also pressure from surrounding communities to manage parking better on campus so that they are not affected by parking spill-over.

Universities are aware of environmental consequences of high dependency on cars and attempt to lower these effects [6]. They want to improve the environment and liveability on campus [8]. Providing better access to the universities is also a concern for the administrators and they want to increase the number of ways for travelling to the campus. Though often overlooked, imparting health benefits to the staff and students are also reasons why universities want to promote active travel [6]. For the staff of The University of Western Australia it was found as the main motivator for using active modes 
including public transport, which was added in the wider definition of active modes in the research. A recent study by Rissel et al. [9] at The University of Sydney, based on a survey of 3,737 students and staff, found that the respondents had higher chance of meeting physical activity recommendation of two and half hours per week if they commuted actively to the campus.

Many universities have managed to decrease the dependence on car and increased the use of public transport, cycling and walking through measures like free public transport passes and increased frequencies, improved pedestrian and cycling facilities, and keeping the supply of parking constant [8]. Stanford University constructed new buildings without increasing the supply of parking and managed to keep the demand for parking to the previous level through TDM measures. Shannon et al. [6] conducted an online questionnaire survey on 1,040 students and 1,170 staff at The University of Western Australia. They found that reducing travel time by bus and bicycle would push their modal share up considerably. They also highlighted the importance of subsidised public transport and better bus service and cycle routes, along with raising the cost of parking. For the students, main motivator for giving up commuting by car was found to be saving money. The intervention that was identified as the most likely to influence commuting behaviour was subsidised public transport pass, for both students and staff.

In the US, universities and public transport agencies have collaborated to provide fare-free bus service to all the students, and in some cases also to staff $[7,10]$. The arrangement is known as the Unlimited Access. Under this arrangement, the universities pay public transport operators the fare for all the trips made by the entitled students and staff. This initiative had effective outcomes in universities across America. For example, bus use increased by more than $50 \%$ and single occupant vehicle trips reduced by $20 \%$ at the University of California at Los Angeles (UCLA) [10]. The findings confirm the importance of cost of travelling in regard to modal choice and highlight the potential of subsidised public transport service for changing commuting practices.

High-occupancy vehicle lanes on busy roads leading to the campus make carpooling more attractive [8]. Ride-sharing can be initiated through a university website linked to database and encouraged by discounted parking fee and guaranteed parking spaces. Car-poolers at the University of Utah at Salt Lake have to pay only the half of the normal parking fee. Though car-pooling is usually encouraged by the universities, not always they will have their own rideshare programs and they might advise students and staff to use the citywide systems [7].

Campus land use planning can help reduce vehicle-km driven, decrease the number of trips, shorten trips for doing essential functions, encourage walking for internal trips through compact form and having facilities at convenient locations [8]. Highly visited facilities like the library be should located at a close proximity to the academic buildings and other services through a high density development. University of Chicago, University of North Carolina, and Clark University present prime examples for this. Students' housing on campus 
significantly impact on their travel behaviour [6]. It enables students to depend on walking for commuting to their schools [8]. However, to promote walking among students on campus, safety and comfort issues have to be addressed properly [7]. It was found that only $3 \%$ of students who lived less than $1 \mathrm{~km}$ distance from the city campus of The University of Western Australia drove to their institution, compared to $40 \%$ who lived within the 1-8 km catchment [6]. Many universities are increasing the supply of student housing to meet various objectives including transportation [8].

Telecommuting can help staff to carry out part of their responsibilities from their home $[8,10]$. Classes might be arranged electronically allowing students to participate interactively in real time from their homes. Video recordings of lectures can be uploaded to websites, which might allow some students not to travel to university if they wanted. Assignments can be arranged to be submitted electronically.

\section{Selection of travel plans}

Considering the scope of this paper, we decided to review the travel plans of five universities. To ensure that potential impacts of the travel plans are huge we considered only the universities, which had more than 20,000 students and were located at or near the CBD of a major city. The University and Auckland was selected automatically as it is the institution where this research originates and it fulfills the criteria. Its neighbouring university, Auckland University of Technology, was also selected. We wanted to include another university from New Zealand and the University of Victoria of Wellington was selected. For similarity in culture and context, it was decided to choose a university, which was geographically close, and RMIT University in Melbourne was included. We wanted to select the fourth one from outside Australasia. We considered universities from both the US and UK. We opted for the University of Leeds in UK as salient features of travel behaviour and travel plans of universities in the US have already been covered in the literature review.

\section{Features of the selected travel plans}

The travel plan of the five universities were developed under different contexts and driven by different objectives. The University of Auckland's (UoA) travel plan was initiated by Auckland Regional Transport Authority (ARTA) under the Travel Wise project, and included the neighbouring Auckland University of Technology (AUT) [11]. It was developed in 2007 and is valid till 2016. Victoria University of Wellington's (VUW) travel plan was developed in 2008 [12]. It was preceded by a scope statement, based on a study conducted by Opus International in 2007 [13]. The Travel Plan for RMIT University was prepared by AECOM Australia for the Swanston Academic Building (SAB) in 2010 [14]. University of Leeds (UL) first prepared a travel plan in 2003, with revisions in 2006, 2009 and 2013. Unlike the other four universities, UL was the author of its travel plan [15]. UL needed to implement a travel plan under Leeds City 
Council's requirement for sites generating high traffic. All the travel plans were based on surveys conducted on the staff and students to capture baseline travel behaviour data. While it is reported that ARTA conducted follow up surveys, but the UoA and AUT combined travel plan has not been updated since 2007. By contrast, UL has been conducting surveys every year. It monitored the effects of travel plan actions, and updated the plan every three years. Table 1 shows the objectives of the four travel plans.

Table 1: Objectives of the four travel plans.

\begin{tabular}{|c|c|}
\hline $\begin{array}{l}\text { Name of the } \\
\text { university }\end{array}$ & Travel plan objectives \\
\hline UoA and AUT & - Universities have excellent transport links \\
\hline VUW & $\begin{array}{l}\text { - Improve environmental performance through } \\
\text { - } \quad \text { Maximum use of sustainable transport } \\
\text { - } \quad \text { Incorporate more effective transport options } \\
\text { - } \quad \text { Provide greater transport choice }\end{array}$ \\
\hline RMIT & $\begin{array}{ll}\text { - } & \text { Improve transport options } \\
\text { - } & \text { Reduce car trips } \\
\text { - } & \text { Encourage use of transport modes with low } \\
\text { environmental impacts } \\
\text { - } & \text { Promote health benefits of active travel } \\
\end{array}$ \\
\hline UL & $\begin{array}{l}\text { - Increase travel choices } \\
\text { - } \quad \text { Promote health benefits } \\
\text { - } \quad \text { Reduce car use, congestion and demand for } \\
\text { - } \quad \text { parking spaces } \\
\text { - Contribute to the } \mathrm{CO}_{2} \text { reduction }\end{array}$ \\
\hline
\end{tabular}

All the universities had quite a few objectives for the travel plan with the exception of UoA and AUT. Travel plans should be driven by objectives as they lead to targets, which could be used to monitor its effectiveness. Monitoring process can result in identification of additional actions or refinement of existing ones, which could help update the plan. The common objective for all the four travel plans is to increase the accessibility to the campus through greater travel choices. Other main aims are to reduce travel by car and increase the share for sustainable modes with a view to decrease congestion, environmental pollution, demand for parking, and improve the health status of the university community.

The surveys conducted for the travel plans revealed the modal shares for car, public transport, walking and cycling for commuting by both staff and students (Table 2). Considering that these universities are located in the CBD, the dependence on cars by the university population is less than the commuters to the CBD. For both staff and students, RMIT has quite low modal shares for cars. It is logical that the RMIT's modal shares for public transport are very high with $80 \%$ of the students commuting to the university by this mode. RMIT 
by trains, trams, and buses, which might have a role in the high modal share for public transport. Cycling is an under used mode at all the universities. There is a potential to improve its status through different measures. In general, students show more sustainable travel behaviour compared to the staff. Therefore, measures for travel behaviour change could be specifically targeted at the staff.

Table 2: Staff and student modal split for commuting trips at the five universities.

\begin{tabular}{|c|c|c|c|c|c|c|c|c|c|c|}
\hline & \multicolumn{2}{|c|}{ Car (\%) } & \multicolumn{2}{|c|}{$\begin{array}{c}\text { Car- } \\
\text { pooling } \\
(\%)\end{array}$} & \multicolumn{2}{|c|}{$\begin{array}{c}\text { Public } \\
\text { transport } \\
(\%)\end{array}$} & \multicolumn{2}{|c|}{$\begin{array}{c}\text { Walking } \\
(\%)\end{array}$} & \multicolumn{2}{|c|}{$\begin{array}{c}\text { Cycling } \\
\text { (\%) }\end{array}$} \\
\hline & $\mathrm{a}$ & $\mathrm{b}$ & $\mathrm{a}$ & $\mathrm{b}$ & $\mathrm{a}$ & $\mathrm{b}$ & $\mathrm{a}$ & $\mathrm{b}$ & $\mathrm{a}$ & $\mathrm{b}$ \\
\hline $\begin{array}{l}\text { UoA and } \\
\text { AUT }\end{array}$ & 25 & 10 & 15 & 13 & 34 & 54 & 12 & 15 & 2 & 2 \\
\hline VUW & 38 & 6 & 8 & 6 & 28 & 47 & 15 & 36 & 5 & 2 \\
\hline RMIT & 9 & 5 & 5 & 5 & 68 & 80 & 5 & 20 & 6 & 0 \\
\hline $\mathrm{UL}$ & 26 & 4 & 12 & 1 & 36 & 19 & 16 & 69 & 9 & 7 \\
\hline
\end{tabular}

Note: $\mathrm{a}=$ staff, $\mathrm{b}=$ student.

Table 3 shows the various measures taken at the five universities, arranged under different TDM approaches. A few measures are common for all the universities, like bicycle racks, and change room and shower facilities for the cyclists, and the awareness initiatives. These are expected due to the low modal share of cycling and its high potential, as evident from the experience of different American universities. It is interesting to note that despite the importance of land use for transportation, land use measures are almost non-existent in the travel plans. Though car-pooling receives mention in the travel plan, none of the universities has developed their own database for ride-sharing, rather the universities advise the staff and the students to use the citywide service. Given the common characteristics of the university population, like the age range of the students and educational qualifications of academic staff, universities should arrange their own ride-matching services.

\section{Conclusion}

Travel plans are being increasingly used by organisations with high number of staff. Due to its student and staff size, universities are huge traffic generators and they have responsibilities for controlling the adverse impacts of traffic. Universities are expected to lead the society to behavioural changes. The travel plans are based on research and universities are ideal places for conducting these studies. Therefore, universities should prepare and implement travel plans and set examples for others to follow suit. 
Table 3: TDM measures at the five universities.

\begin{tabular}{|c|c|c|c|c|c|}
\hline TDM aspects & TDM measures & $\begin{array}{c}\text { UoA and } \\
\text { AUT }\end{array}$ & VUW & RMIT & $\mathbf{U L}$ \\
\hline \multirow[t]{5}{*}{$\begin{array}{l}\text { Public } \\
\text { transport }\end{array}$} & Subsidised fare & $\sqrt{ }$ & $\sqrt{ }$ & $\begin{array}{l}\sqrt{ } \text { (only } \\
\text { for staff) }\end{array}$ & $\begin{array}{l}\sqrt{ } \text { (only } \\
\text { for staff) }\end{array}$ \\
\hline & Shuttle bus & $\sqrt{ }$ & $\sqrt{ }$ & $\mathrm{x}$ & $\mathrm{x}$ \\
\hline & $\begin{array}{l}\text { High frequency } \\
\text { services }\end{array}$ & $\mathrm{x}$ & $\mathrm{x}$ & $\mathrm{x}$ & $\mathrm{x}$ \\
\hline & $\begin{array}{l}\text { Lot of routes } \\
\text { servicing the } \\
\text { campus }\end{array}$ & $\sqrt{ }$ & $\sqrt{ }$ & $\mathrm{x}$ & $\mathrm{X}$ \\
\hline & $\begin{array}{l}\text { Bus stops on } \\
\text { campus }\end{array}$ & $\sqrt{ }$ & $\mathrm{x}$ & $\mathrm{x}$ & $\mathrm{X}$ \\
\hline \multirow[t]{4}{*}{ Cycling } & $\begin{array}{l}\text { Dedicated cycle } \\
\text { lanes }\end{array}$ & $\sqrt{ }$ & $\mathrm{x}$ & $\mathrm{x}$ & $\sqrt{ }$ \\
\hline & Bicycle racks & $\sqrt{ }$ & $\sqrt{ }$ & $\sqrt{ }$ & $\sqrt{ }$ \\
\hline & $\begin{array}{l}\begin{array}{l}\text { Change rooms/ } \\
\text { shower facilities }\end{array} \\
\end{array}$ & $\sqrt{ }$ & $\sqrt{ }$ & $\sqrt{ }$ & $\sqrt{ }$ \\
\hline & $\begin{array}{l}\text { Free cycle for } \\
\text { campus use (or by } \\
\text { coins) }\end{array}$ & $\mathrm{x}$ & $\mathrm{x}$ & $\begin{array}{l}\sqrt{ } \text { (for work } \\
\text { related } \\
\text { travel only) }\end{array}$ & $\mathrm{x}$ \\
\hline \multirow[t]{3}{*}{ Walking } & $\begin{array}{l}\text { Direct and safe } \\
\text { routes inside campus }\end{array}$ & $\sqrt{ }$ & $\sqrt{ }$ & $\mathrm{x}$ & $\sqrt{ }$ \\
\hline & $\begin{array}{l}\text { Pedestrian } \\
\text { preference at } \\
\text { intersections }\end{array}$ & $\sqrt{ }$ & $\mathrm{x}$ & $\mathrm{x}$ & $\mathrm{x}$ \\
\hline & $\begin{array}{l}\text { Speed limit for } \\
\text { motorised vehicles }\end{array}$ & $\sqrt{ }$ & $\mathrm{x}$ & $\mathrm{x}$ & $\mathrm{x}$ \\
\hline $\begin{array}{l}\text { Scooters/ } \\
\text { motorbike }\end{array}$ & $\begin{array}{l}\text { Scooter parking } \\
\text { spaces }\end{array}$ & $\sqrt{ }$ & $\sqrt{ }$ & $\mathrm{x}$ & $\sqrt{ }$ \\
\hline \multirow[t]{3}{*}{ Ride-sharing } & Car-pooling schemes & $\begin{array}{l}\sqrt{ } \text { (rideshare } \\
\text { matching for } \\
\text { staff) }\end{array}$ & $\sqrt{ }$ & $\sqrt{ }$ & $\sqrt{ }$ \\
\hline & $\begin{array}{l}\text { Preferential parking } \\
\text { for car-poolers }\end{array}$ & $\mathrm{x}$ & $\mathrm{x}$ & $\sqrt{ }$ & $\mathrm{x}$ \\
\hline & Database & $\mathrm{x}$ & $\sqrt{ }$ & $\mathrm{x}$ & $\mathrm{x}$ \\
\hline \multirow{3}{*}{$\begin{array}{l}\text { Operation of the } \\
\text { university }\end{array}$} & Night classes & $\mathrm{x}$ & $\mathrm{x}$ & $\mathrm{x}$ & $\mathrm{x}$ \\
\hline & Staggered classes & $\mathrm{x}$ & $\mathrm{x}$ & $\mathrm{x}$ & $\mathrm{x}$ \\
\hline & $\begin{array}{l}\text { Work from home } \\
\text { (incl. teleconference) }\end{array}$ & $\sqrt{ }$ & $\sqrt{ }$ & $\sqrt{ }$ & $\mathrm{x}$ \\
\hline Student housing & $\begin{array}{l}\text { Residential accom- } \\
\text { modation on campus }\end{array}$ & $\sqrt{ }$ & $\mathrm{x}$ & $\mathrm{x}$ & $\mathrm{x}$ \\
\hline \multirow[t]{2}{*}{ Parking } & $\begin{array}{l}\text { Reduced car parking } \\
\text { space }\end{array}$ & $\begin{array}{l}\text { Ongoing } \\
\text { review }\end{array}$ & $\mathrm{x}$ & $\mathrm{x}$ & $\begin{array}{l}\sqrt{ } \\
\text { (student } \\
\text { car } \\
\text { parking } \\
\text { facilities } \\
\text { withdrawn } \\
\text { in 2000) } \\
\end{array}$ \\
\hline & High parking charge & $\begin{array}{l}\text { Ongoing } \\
\text { review }\end{array}$ & $\mathrm{x}$ & $\mathrm{x}$ & $\sqrt{ }$ \\
\hline
\end{tabular}


Table 3: Continued.

\begin{tabular}{|c|c|c|c|c|c|}
\hline TDM aspects & TDM measures & $\begin{array}{c}\text { UoA and } \\
\text { AUT }\end{array}$ & VUW & RMIT & $\mathbf{U L}$ \\
\hline \multirow{2}{*}{ Land use } & Compact campus & $\mathrm{x}$ & $\mathrm{x}$ & $\mathrm{x}$ & $\mathrm{x}$ \\
\hline & $\begin{array}{l}\text { Central location of } \\
\text { student facilities }\end{array}$ & $\mathrm{x}$ & $\mathrm{x}$ & $\mathrm{x}$ & $\mathrm{x}$ \\
\hline \multirow[t]{2}{*}{ Awareness } & Campaign & $\mathrm{x}$ & $\sqrt{ }$ & $\sqrt{ }$ & $\sqrt{ }$ \\
\hline & $\begin{array}{l}\text { Brochures/posters/ } \\
\text { web pages/meetings }\end{array}$ & $\sqrt{ }$ & $\sqrt{ }$ & $\sqrt{ }$ & $\sqrt{ }$ \\
\hline \multirow[t]{3}{*}{ Administrative } & $\begin{array}{l}\text { Different committees } \\
\text { involving } \\
\text { stakeholders }\end{array}$ & $\mathrm{x}$ & $\sqrt{ }$ & $\mathrm{x}$ & $\sqrt{ }$ \\
\hline & $\begin{array}{l}\text { Environmentally } \\
\text { friendly fleet }\end{array}$ & $\mathrm{x}$ & $\begin{array}{l}\sqrt{ } \text { (just } \\
\text { consideri } \\
\text { ng) }\end{array}$ & $\begin{array}{l}\sqrt{ } \text { (at least } \\
\text { one energy } \\
\text { efficient fleet } \\
\text { vehicle in } \\
2012) \\
\end{array}$ & $\sqrt{ }$ \\
\hline & $\begin{array}{l}\text { Dedicated staff } \\
\text { overseeing travel plan } \\
\text { implementation }\end{array}$ & $\mathrm{x}$ & $\mathrm{x}$ & $\mathrm{x}$ & $\sqrt{ }$ \\
\hline
\end{tabular}

Travel plans can benefit the university, community and staff and students. It can help a university to improve access to campus and its liveability, enhance its image, improve its relationship with the neighbourhood community, and reduce expenditure on the provision and maintenance of parking facilities. The community can benefit through reduced congestion on road network, lowered pollution level, control of parking spill-over, and better transportation infrastructure and services. The staff and students can benefit by more travel choices, reduced commuting time and costs, less stress and positive health outcomes.

Travel plans are usually based on various TDM measures. This paper discussed various TDM measures from sustainability perspectives and the transport initiatives of universities. It then reviewed the travel plans of five universities, compared their characteristics, and identified common as well as uncommon measures and overlooked measures. Since travel plan is a relatively new tool, this paper should help universities to develop and update travel plans with a view to modifying student and staff behaviour towards sustainable practices, accruing different kinds of benefits through the process.

\section{References}

[1] Mahmood, M., Bashar, M. A. \& Akhter, S., Travel Demand Management (TDM) for Improved Transportation System: Lessons for Bangladesh. Journal of Quality and Technology Mangement, IV(II), pp. 26-43, 2008. 
[2] Mahmood, M., Bashar, M. A. \& Akhter, S., Traffic Management System and Travel Demand Management (TDM) Strategies: Suggestions for Urban Cities in Bangladesh. Asian Journal of Management and Humanity,. 4(2-3), pp. 161-178, 2009.

[3] Schiller, P. L., Bruun, E. C. \& Kenworthy, J. R., An Introduction to Sustainable Transportation: Policy, Planning and Implementation, Earthscan: London, 2010.

[4] Banister, D. \& Marshall, S., Encouraging Transport Alternatives: Good Practice in Reducing Travel, The Stationery Office: London, 1999.

[5] Enoch, M. \& Zhang, L., Travel Plans (Chapter 12). The Implementation and Effectiveness of Transport Demand Management Measures: An International Perspective, eds. S. Ison \& T. Rye, Ashgate: Aldershot, England, pp. 233-255, 2008.

[6] Shannon, T., et al., Active Commuting in A University Setting: Assessing Commuting Habits and Potential for Modal Change. Transport Policy, 13(3), pp. 240-253, 2006.

[7] Balsas, C. J., Sustainable Transportation Planning on College Campuses. Transport Policy, 10(1), pp. 35-49, 2003.

[8] Toor, W. \& Havlick, S., Transportation and Sustainable Campus Communities: Issues, Examples, Solutions, Island press: Washington, 2004.

[9] Rissel, C., Mulley, C. \& Ding, D., Travel Mode and Physical Activity at Sydney University. International Journal of Environmental Research, 10, pp. 3563-3577, 2013.

[10] Brown, J., Hess, D. \& Shoup, D., Fare-Free Public Transit at Universities: An Evaluation. Journal of Planning Education and Research, 23(1), pp. 69-82, 2003.

[11] Auckland Regional Transport Authority, The Universities' Travel Plan 2007-2016: A TravelWise Project for The Learning Quarter, Auckland Regional Transport Authority: Auckland, 2006.

[12] Opus International Consultants, Victoria University of Wellington Travel Plan: Vic Commute, Victoria University of Wellington: Wellington, 2008.

[13] Opus International Consultants, Victoria University Travel Plan: Scope Statement, Opus International Consultants: Auckland, 2007.

[14] AECOM Australia, RMIT Swanston Academic Building Travel Plan, Lyons Architects: Melbourne, 2010.

[15] University of Leeds, University of Leeds: Travel Plan, University of Leeds: Leeds, 2013. 